\title{
AC 2007-392: THE DIFFERENTIAL EFFECTS OF FEMALE ONLY VS. CO-ED ENRICHMENT PROGRAMS ON MIDDLE SCHOOL STUDENTS' ATTITUDES TOWARD SCIENCE, MATHEMATICS AND ENGINEERING
}

\author{
Linda Hirsch, New Jersey Institute of Technology \\ DR. LINDA S. HIRSCH is the Program Evaluator in the Center for Pre-College programs. She \\ has a doctoral degree in educational psychology with a specialty in psychometrics and a Masters \\ degree in statistics. She has been involved in all aspects of educational and psychological \\ research for 15 years. Dr. Hirsch has extensive experience conducting longitudinal research \\ studies and is proficient in database management, experimental design, instrument development, \\ psychometrics and statistical programming.
}

John Carpinelli, New Jersey Institute of Technology

JOHN D. CARPINELLI is an Associate Professor of Electrical and Computer Engineering and Director of the Center for Pre-College Programs at the New Jersey Institute of Technology. He previously served as coordinator of activities at NJIT for the Gateway Engineering Education Coalition and as a member of the Coalition's Governing Board. He currently chair's NJIT's Excellence in Teaching Awards Committee and is past chair of the University Master Teacher Committee.

\section{Howard Kimmel, New Jersey Institute of Technology}

HOWARD KIMMEL is Professor of Chemical Engineering and Executive Director of the Center for Pre-College Programs at New Jersey Institute of Technology. He has spent the past thirty years designing and implementing professional development programs and curricula for K-12 teachers in science and technology. At the college level, he collaborates on projects exploring teaching methodologies and assessment strategies in first-year college courses in the sciences, engineering, and computer science.

\section{Ronald Rockland, New Jersey Institute of Technology}

RONALD H. ROCKLAND is Associate Dean of the Newark College of Engineering, and an Associate Professor of Engineering Technology and Biomedical Engineering. He received a B.S.E.E. and M.S.E.E. and Ph.D. in bioengineering and electrical engineering from New York University in 1967, 1969 and 1972 respectively. He also received an M.B.A. in marketing from the University of St. Thomas in 1977. He is a 2000 award winner in Excellence in Teaching for NJIT, and the chair of the Master Teacher's committee. Dr. Rockland has over 20 years of industrial experience in research, engineering, marketing and sales management with several high technology corporations.

\section{Joel Bloom, New Jersey Institute of Technology}

JOEL BLOOM is Vice President for Academic \& Student Services, and Dean of the Albert Dorman Honors College. He received a master's degree and a doctorate from Teachers College, Columbia University. From 1983 through 1990, Dr. Bloom served as assistant commissioner in the NJ Department of Education for the Division of General Academic Education, where he was responsible for managing many of the education department's initiatives (competency testing, curriculum content standards, pre-school programs, and establishment of model effective schools). 


\title{
The Differential Effects of Female Only vs. Co-ed Enrichment Programs on Middle School Students' Attitudes to Science, Mathematics and Engineering
}

\begin{abstract}
The Center for Pre-College Programs at New Jersey Institute of Technology offers a series of summer programs designed to increase academically talented students' interest in the fields of science, mathematics, engineering and technology in an effort to increase the number of young students, particularly girls and other traditionally underrepresented minorities, who pursue technological careers. One program in particular, Woman in Engineering and Technology, called FEMME, was designed specifically for young women in an effort to increase the number of women interested in engineering and other technological careers. Most of the programs span grades four to eight because middle school is such an important time for all students to begin thinking about future careers. Research on engineering recruitment indicates that many students, particularly young girls, do not know about engineering careers and have few adults or peers discussing careers in engineering with them. As a result not enough students explore engineering or other technical fields as a career option and therefore do not prepare academically. Programs such as those offered by the Center for Pre-College Programs can be instrumental in informing young students about careers in engineering and technology and assure they receive the academic background required to study for these careers in college. Further, because boys and girls do not differ much in technical abilities but rather in their attitudes toward technological careers including engineering until the later high school years, single-gender programs like FEMME can be particularly effect in reaching young girls and changing their attitudes. Initial evaluations of the FEMME program have been positive but they have been primarily formative in nature. The Middle School Students' Attitude to Engineering, Science and Mathematics Survey has been developed to measure middle school students' overall attitudes to engineering, mathematics and science; their knowledge about engineering careers; their self-efficacy in relation to engineering and technology-related skills and who is talking to them about careers in engineering. All students who attended one of the 2006 summer programs at the Center for Pre-College Programs were asked to complete the survey at the beginning and again at the end of their program. Repeated measures analysis of variance techniques were used to examine students' responses and test for 1) significant increases in students' attitudes toward science, mathematics and engineering and their knowledge about careers in engineering from the beginning to the end of the program, 2) significant differences in attitude and knowledge between boys and girls, and 3) significant difference between the girls in the single-gender FEMME programs and the girls who attended the other mixed-gender programs.
\end{abstract}

\section{Introduction}

Current trends in the supply of and need for engineers in the workforce portend a significant shortfall of qualified engineering practitioners in the not too distant future. Although demand for engineers is expected to increase faster than for any other profession by $2010^{1}$, the number of students studying engineering has not changed significantly in the past decade ${ }^{2}$. As the baby boomer generation begins to retire, this lack of growth in enrollments in engineering programs will have an even greater impact. The under representation of female students is a chronic 
contributing factor to the lack of enrollment increases. Less than $10 \%$ of engineers in the United States are female ${ }^{3}$, and this percentage does not appear to be changing ${ }^{4}$.

The lack of interest in studying engineering is not receding. A nationwide survey of students taking the PSAT in 2002-2003 found only $16 \%$ of male students and a miniscule $2 \%$ of female students intending to study engineering in college ${ }^{5}$. Increasing the interest of female students in pursuing engineering studies will be an important strategy to increase overall enrollment in undergraduate engineering programs.

Several factors influence a student's choice of career, including how they assess their own skills and interests and relate them to job prospects in the current and future workforce. Many students simply lack the mathematics and science prerequisites needed to enter and complete undergraduate engineering programs. Most students also do not know what engineering is and what engineers do, and their parents, teachers, and school counselors often do not know enough about engineering to help inform students ${ }^{6-9}$. Unlike many professions, engineers are rarely depicted in movies and television shows. The engineers in the Dilbert ${ }^{\circledR}$ comic strip may be funny, but they do not reflect the typical engineering workplace and do not persuade students to study engineering.

Inadequate academic preparation and lack of information about engineering are the most crucial reasons why students do not pursue engineering careers ${ }^{10}$, but even students with adequate preparation who pursue engineering studies often do not persist in their programs. Numerous studies of students who dropped out of engineering programs have determined that poor preparation and lack of information account for only a part of the reason why students leave engineering programs. Other factors that have been identified even among students that left engineering programs while in good academic standing include lack of interest, poorer attitudes toward engineering, general impressions of engineering, and less positive perceptions of the work engineers do. ${ }^{11-19}$ To address these factors, students need not only be better prepared in math and science prior to entering engineering programs, but should also be more well-informed about engineers and engineering and should have more positive attitudes toward engineering. This will ensure not only that more students choose engineering studies, but also that more students succeed in engineering.

The attitudes of female students start to change during middle school even though boys and girls are relatively equal in ability through their elementary school years ${ }^{20,21}$. Studies indicate that girls start to underestimate their own technical abilities in high school, enrolling in fewer mathematics and science courses and thus lack the background needed to enter engineering programs $^{22}$. Early intervention is needed to address this problem because once the female students reach college it is too late ${ }^{23}$.

Many students, particularly female students, develop negative impressions about engineering work conditions that steer them away from engineering careers. Many often believe that other fields with greater female representation offer less gender discrimination and greater opportunities for achievement ${ }^{24}$, or feel that engineering work is incompatible with family life and that the monetary rewards do not justify the effort involved ${ }^{25,26}$. 
Women tend to be attracted to fields that contribute to society, such as medicine, psychology, or teaching and there has been a significant increase in women entering health related fields ${ }^{27}$. The engineering field most closely related to medicine is biomedical engineering. Although only about $20 \%$ of bachelors degrees in engineering have been awarded to women in the past five years, almost $46 \%$ of biomedical engineering degrees were earned by women ${ }^{28}$. The difference in percentages may be due to the easily recognized impact of health related fields on improving the quality of life.

Although engineering is still a male-dominated field, gender discrimination in engineering wages has been almost eliminated, with women earning approximately $95 \%$ of the wages earned by men $^{29}$. To encourage more female students to pursue engineering studies, it is essential to eliminate misinformation and negative impressions about engineers and engineering ${ }^{4}$. Women who have succeeded in engineering should serve as a role model to young girls. Research has shown that many students who study engineering have influential role models ${ }^{30}$ and girls who study engineering often have fathers who are engineers ${ }^{31}$.

\section{Background}

The Center for Pre-College Programs (CPCP) was established in 1978 at New Jersey Institute of Technology with the mission to provide all students with equal access to high quality science, technology, engineering and mathematics (STEM) education, mentorship activities and peer support, allowing underrepresented groups to see the rewards that STEM careers can bring. Students who participate in pre-college programs are better prepared to pursue and successfully graduate in STEM majors. Among the many programs offered by CPCP is the Woman in Engineering and Technology program (FEMME) $)^{23}, 32$ established in 1981 to improve the science, mathematics and technology skills of young women in an effort to increase the number of women interested in engineering and other technological careers. The FEMME program, which spans grades four to eight because the middle school years have been found to be such an important time for all students to begin thinking about future careers, is an intensive four-week summer program designed to 1) enhance science and mathematics achievement, 2) develop critical thinking and problem solving skills, 3) increase interest in engineering and other high tech fields, and 4) increase enrollment in advanced placement science and mathematics courses in high school. In addition to classroom learning and laboratory experiments, the girls participate in counseling sessions and go on field trips. The girls are introduced to female engineers and have the opportunity to see first hand the career options available to them. The academic curriculum for each FEMME group is grade appropriate and aligned with New Jersey State Core Curriculum standards but the focus of each group is different. For example, the post fourth-graders (FEMME4) focus on Environmental Science, FEMME5: Aerospace Engineering, FEMME6; Mechanical Engineering, FEMME7; Chemical Engineering, and FEMME8;

Biomedical Engineering. Although there is some debate about the overall effectiveness of single gender educational environments ${ }^{33}$ research has shown that girls appear to be more comfortable contributing to classroom discussions, asking questions, and participating in activities; and develop more positive attitudes toward mathematics and science in single gender environments.

Initial evaluations of the FEMME program were positive but primarily formative in nature. ${ }^{34}$ Girls participating in FEMME programs were found to have positive attitudes toward 
engineering and follow-up studies of program participants who had completed high school found exceedingly high proportions (over 60\%) reporting that they were either currently enrolled in a technology based degree program or had chosen a career path in engineering, mathematics, science or computer technology ${ }^{33,34}$. During the summers of 2003 and 2005 one hundred seventy eight (178) girls in the in the FEMME programs took the Middle School Attitude to Engineering, Science and Mathematics Survey. ${ }^{35}$ During the same time periods 111 boys and 124 girls from similar backgrounds (including some of the same schools) also took the survey and the girls in the FEMME programs had significantly more positive attitudes toward engineering, engineering, science and mathematics and had significantly more knowledge of engineering careers compared to the other female and male students ${ }^{35}$.

Some of the other summer programs offered by CPCP are:

Aeronautical Engineering Program (AEP) a five-week program designed to provide post-fifth grade students (male and female) with an introduction to Aeronautical Engineering. Students have the opportunity to enhance their mathematics, science and technological academic achievement, develop problem-solving and critical thinking skills through classroom discussions, hands-on laboratory experimentation, computer activities and field trips.

Junior Pre-engineering Program (PrEP) a five-week project designed to provide post-6th grade students with an introduction to various disciplines in engineering. PrEP curricula encompass principles of engineering that gives students an opportunity to enhance their mathematics, science, and technological academic achievement, develop problem-solving and critical thinking skills, and learn about careers in engineering, science and technology.

Algebra Prep Program (APP) is a five-week preparatory program for post-7th and post-8th grade students who will be enrolling in Algebra I, a cornerstone of the secondary school mathematics curriculum. Participants learn algebra, communication skills, computer applications, conduct hands-on activities, and are encouraged to choose advanced mathematics and college preparatory courses in high school.

Introduction to Chemical Industry for Minorities in Engineering Program (IChIME) is a four-week project designed to give post-eighth grade urban students an opportunity to increase their awareness and understanding of chemistry and chemical engineering. IChIME activities use problem solving, computer applications and collaborative learning to show the role of chemical engineers and scientists (chemists) as problem solvers.

Explore Careers in Technology and Engineering Program (ExCITE) is a five-week, postseventh grade program designed to encourage students to learn about careers in technology and engineering. Students participate in a series of academic modules in diverse areas of engineering and technology including Environmental, Aeronautical, Chemical, Biomedical, and Computer Science and receive test preparation training for the New Jersey Grade Eight Proficiency Assessment.

During the summer of 2006 students in the FEMME, APP, AEP, PrEP, IChIME, and ExCITE programs completed the Middle School Attitudes to Mathematics, Science and Engineering Survey at both the beginning and end of their respective programs. The survey provides measures of students': 
- Attitudes to Engineering, Science and Mathematics: Students indicate the degree to which they agree or disagree with statements about science, mathematics, engineering and the kinds of things that engineers do such as "engineers help make peoples lives better" on a five-point scale where 1 indicates strong disagreement and 5 indicates strong agreement. A sixth point, scored as zero (0), allows students to indicate they "do not know". In addition to an overall measure of attitudes (TOTAL), the current version of the survey has an interest in engineering subscale (INTEREST), positive opinions subscale (POSITIVE), negative stereotype subscale (NEGATIVE), problem-solving and technical skills subscale (TECHNICAL), a gender equity subscale (GENDER) and a general subscale (GENERAL).

- Knowledge of Engineering Careers: A multi-part open-ended question asks students to "Name five different types of engineers" and to "give an example of the work done by each type". Each type is coded " 1 ' for correct and " 0 " for incorrect. Possible total scores for TYPE range from zero to five. Each example of the work they do is coded " 2 " for completely correct, "1" for partly correct, and "0" for incorrect. Possible total scores for EXAMPLE range from zero to ten.

Students are also asked if they have participated in other CPCP programs prior to their current program, who they may have talked to about careers in engineering, and how often they have heard about careers in engineering in the media.

The current paper is a summary of the changes in all students' attitudes and knowledge of engineering careers from the beginning to the end of each program. Repeated measures analysis of variance techniques are used to test for significant changes in students' attitudes from the beginning to the end of their respective program(s) and whether the changes were relatively the same within each program or if some programs, particularly the FEMME programs, effected more change than others. Chi-square tests are used to examine whether students' responses to the Knowledge of Engineering Careers question indicated they had significantly more knowledge at the end of their respective program than at the beginning.

\section{Results}

Two hundred forty-four students enrolled in 10 different programs at CPCP during the summer of 2006 completed the Middle School Attitudes to Science, Mathematics and Engineering Survey at both the beginning and end of their respective program; an additional 6 took the survey at the beginning but not the end of their program(s) and another 4 took the survey only at the end of their program(s) for a total of 254 students. Table I is a summary of the number of students taking the survey in each program, the gender composition and the percentage indicating they had attended a CPCP program prior to their current program. The ethnic diversity of the students in the programs was quite exceptional; most programs were less than $20 \%$ Caucasian, approximately $15 \%$ Asian, approximately $25-30 \%$ each African American and HispaniclLatino, and another $5-10 \%$ in each program self-identified as Mixed\Biracial or other.

\section{Attitudes to Mathematics, Science and Engineering}

Repeated measures analysis of variance techniques were used to test for changes in students' Attitudes to Science, Mathematics and Engineering from the beginning to the end of their 
programs for the 244 students who completed the survey on both occasions and to determine if changes in students' attitudes were different with any of the 10 individual programs. In general students' attitudes did not change and no significant differences were found among the 10 different programs although their attitudes were generally more positive than prior research indicates for the average middle school student. ${ }^{8,35}$

Table I

Summary of Programs Students Attended, Gender and Attendance in Prior Programs

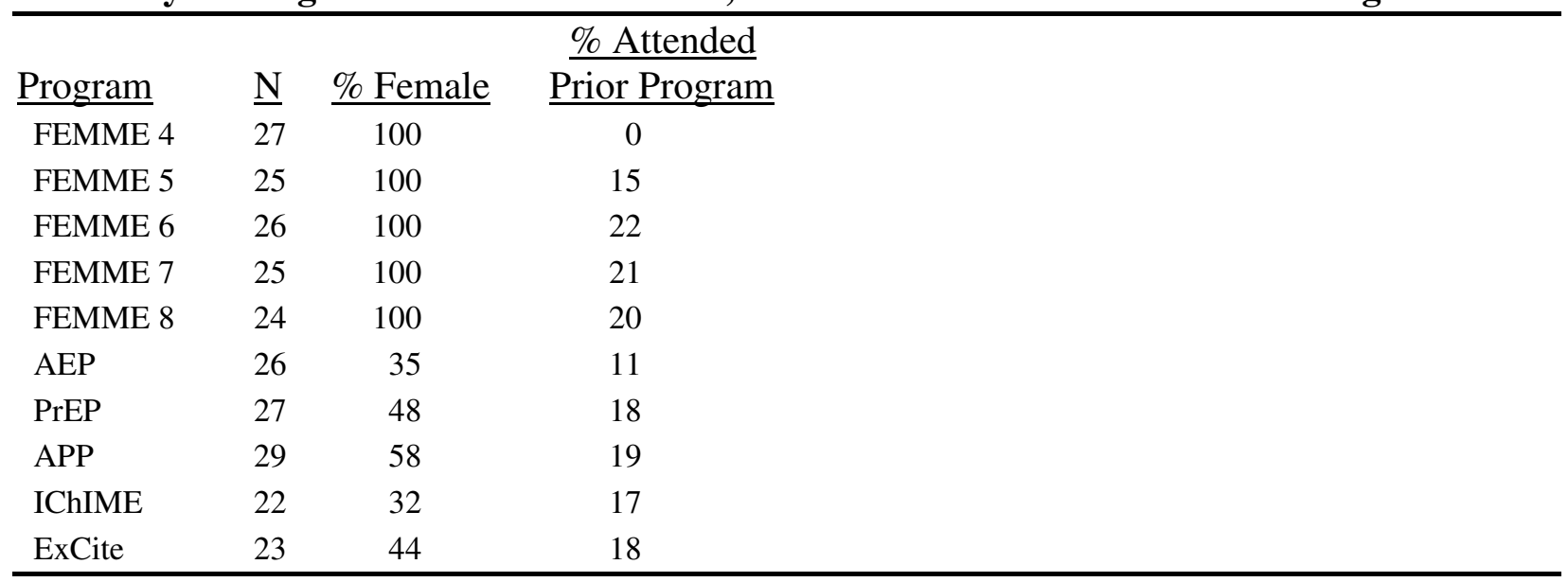

When the attitudes to mathematics, science and engineering for the girls in all five FEMME programs were compared as a whole to the attitudes of the students in the five mixed gender programs combined significant differences were found on the gender equity subscale (i.e. Girls can do math and science just as well as boys $)\left(\mathrm{F}_{1,241}=6.17, \mathrm{p}=.01\right)$ and the negative stereo-type subscale (i.e. Only nerds spend a lot of time doing math and science; Engineers are just people who do a lot of science) $\left(\mathrm{F}_{1,239}=5.44, \mathrm{p}=.02\right)$ (see Table II).

Table II

Summary of Changes in Attitudes to Mathematics, Science and Engineering From the Beginning to the End of the Summer Programs

\begin{tabular}{|c|c|c|c|c|c|}
\hline & \multicolumn{2}{|c|}{$\underline{\text { FEMME }}$} & \multicolumn{2}{|c|}{ MIXED GENDER } & \\
\hline & $\underline{\text { Beginning }}$ & $\underline{\text { End }}$ & $\underline{\text { Beginning }}$ & $\underline{\text { End }}$ & \\
\hline & Mean (SD) & Mean (SD) & Mean (SD) & Mean (SD) & p-value \\
\hline $\begin{array}{l}\text { TOTAL scale } \\
\text { Subscales }\end{array}$ & $3.64 \quad(.37)$ & $3.65 \quad(.39)$ & $3.64 \quad(.38)$ & $3.64 \quad(.54)$ & .75 \\
\hline INTEREST & $3.02 \quad(.73)$ & $2.96 \quad(.74)$ & $3.05 \quad(.74)$ & $3.09 \quad(.72)$ & .08 \\
\hline POSITIVE & $3.31 \quad(.74)$ & $3.35 \quad(.75)$ & $3.55 \quad(.76)$ & $3.48 \quad(.81)$ & .14 \\
\hline NEGATIVE* & $1.85 \quad(.49)$ & $1.82(.54)$ & $2.01 \quad(.56)$ & $2.16 \quad(.69)$ & .01 \\
\hline TECHNICAL & $3.78 \quad(.65)$ & $(.69)$ & $3.92 \quad(.58)$ & $3.85 \quad(.67)$ & .25 \\
\hline GENDER & $4.67 \quad(.58)$ & $(.57)$ & $4.33 \quad(.89)$ & $4.21 \quad(.92)$ & .02 \\
\hline GENERAL & $3.83 \quad(.75)$ & $3.97 \quad(.68)$ & $3.98 \quad(.61)$ & $4.03 \quad(.61)$ & .48 \\
\hline
\end{tabular}

* Subscale items are phrased negatively, so a lower mean is desirable. 
The average response to the gender equity subscale for the girls in the FEMME programs increased from 4.67 to 4.78 while the average response from the students in the other five programs decreased from 4.33 to 4.21 . Further examination of the responses from the males and females within the mixed gender programs showed that the average response from the females in the mixed gender programs decreased significantly from 4.82 to 4.59 while the average response from the males in the mixed gender programs did not change significantly, 3.95 vs. 3.92.

The average response to the negative stereo-type subscale for the girls in the FEMME programs decreased slightly from 1.85 to 1.82 while the average response from students in the other five programs increased from 2.01 to 2.16. Further examination of the responses from the males and females within the mixed gender programs showed that the average response from the females in the mixed gender programs increased significantly from 1.93 to 2.10 while the average response from the males in the mixed gender programs did not change significantly, 2.15 vs. 2.20.

As mentioned previously, the overall attitudes to mathematics, science and engineering for the current group of students were relatively positive compared to the average middle school even at the beginning of the summer programs which did not afford much room for change. Further examination of the demographic data collected for each student found that $117(46 \%)$ indicated they had attended a summer program at CPCP prior to the current program; in fact $29 \%$ indicated they had attended one prior program, $9 \%$ indicated they had attended two prior programs and $8 \%$ indicated they had attended three prior programs. Therefore, comparisons were made between the students who had previously attended a CPCP program and those who had not but no significant differences were found.

\section{Knowledge of Engineering Careers}

The distributions of scores for each part of the Knowledge of Engineering Careers question were not normally distributed so it was not possible to calculate mean numbers of correct responses for either part of the question. Chi-Square Tests of Independence were used to compare the distributions of scores at the beginning of the programs to the distributions of scores at the end of the programs.

Significant differences in the responses to the first part of the Knowledge of Engineering Careers question "Name Five Different Types of Engineers" were found from the beginning to the end of the programs $\left(\boldsymbol{X}^{2}{ }_{3}=9.6, \mathrm{p}=.02\right)$. See Table III for a complete summary of all responses. The students in the current sample were able to name more types of engineers than the average middle school student. ${ }^{8,35}$ The only significant differences among the 10 different programs were for the girls in the FEMME 4 program and the students in the AEP program. None of the post-fourth graders in the FEMME 4 program had taken a prior CPCP course and only 3 of the post-fifth grader girls had been in the FEMME 4 program so the students in those two programs had higher percentages of students who were not able to name any type of engineer. Most of these students were able to name at least 3-4 types of engineers, if not 5, at the end of the program whereas there was not much of a change in any of the other programs. 
Table III

Students' Responses to the Knowledge of Engineering Careers Question: Part 1, Name Five Different Types of Engineers.

\begin{tabular}{lcccc}
\hline & \multicolumn{4}{c}{ Number Correct Responses } \\
& 0 & $1-2$ & $3-4$ & 5 \\
Beginning of Programs & $18 \%$ & $31 \%$ & $33 \%$ & $18 \%$ \\
End of Programs & $12 \%$ & $24 \%$ & $37 \%$ & $27 \%$ \\
\hline
\end{tabular}

No significant differences in the responses to the second part of the Knowledge of Engineering Careers question "Give an Example of the Work Done by Each Type of Engineer" were found from the beginning to the end of the programs $\left(\boldsymbol{X}^{2}{ }_{3}=4.1, \mathrm{p}=.26\right)$. See Table IV for a complete summary of all responses. Again, the students in the current sample were able to give many more examples of the work done by engineers than the average middle school student ${ }^{8,35}$ but no significant differences were found among the 10 different programs. The proportion of students in each program that were not able to give any examples of the work done by each type of engineer was not significantly higher than that for the girls in the FEMME 4 program or the students in the AEP program.

Table IV

Students' Responses to the Knowledge of Engineering Careers Question: Part 2, Give an Example of the Work Done by Each Type of Engineer

\begin{tabular}{lcccc}
\hline & \multicolumn{5}{l}{ Number of Points } \\
& 0 & $1-4$ & $5-8$ & $9-10$ \\
Beginning of Programs & $33 \%$ & $58 \%$ & $9 \%$ & $<1 \%$ \\
End of Programs & $35 \%$ & $52 \%$ & $12 \%$ & $1 \%$ \\
\hline
\end{tabular}

\section{Conclusions}

Results of the current study are positive but not necessarily as informative as had been expected. Students in the CPCP summer programs were found to have Attitudes to Science, Mathematics and Engineering which appear to be more positive than for most middle school students and they displayed much more Knowledge of Engineering Careers. So although these results may be positive, not much evidence could be found to indicate students' attitudes to mathematics, science and engineering or knowledge of engineering careers changed significantly as a result of attending one of the 2006 summer programs, as their attitudes and knowledge were already higher than for most middle school students. In retrospect, this is a high achieving group of students in that acceptance into any of the programs requires a minimum grade point average of 3.0 in mathematics and science and three letters of recommendation; One each from their science and mathematics teachers and their school guidance counselor. At least $98 \%$ of the students in each program agreed or strongly agreed with the item on the GENERAL subscale that "When I am old enough I will go to college" and almost half of them had already attended another CPCP summer program. 
Some differential effects were found between the FEMME programs and the mixed gender programs. Girls in the FEMME program had significantly lower scores on the negative stereotype subscale and significantly higher scores on the gender equity subscale of the Attitudes to Mathematics, Science and Engineering Survey. By the end of the summer girls in the FEMME programs more strongly agreed with the notion that girls are just as good as boys in the areas of mathematics and science than the girls in the mixed gender programs and they disagreed more with the negative stereo-types that exist about engineers lending more credibility to conclusions drawn from previous research that girls benefit more from female only educational experiences. ${ }^{33-35}$

\section{Bibliography}

[1] National Science Board. Science and engineering indicators 2004, Arlington, VA: National Science Foundation, 2004 (NSB-00-1).

[2] National Academy of Engineering. Raising Public Awareness of Engineering. The National Academies Press. Washington, D.C. 2002.

[3] New Jersey Commission on Higher Education. Higher education outcomes and high-tech workforce demands. The fifth annual system wide accountability report. 2001.

[4] JobWeb.com - Career development and job search help for college students. Copyright National Association of Colleges and Employers. Retrieved March 2007 from http://www.jobweb.com.

[5] The College Board PSAT / NMSQT Summary Report, (2002-2003).

[6] Gibbons, S., J., Hirsch, L., S., Kimmel, H., Rockland, R. and Bloom, J. (2003). "Counselors Attitudes and Knowledge About Engineering”. Proceedings of the 2003 International Conference on Engineering Education, Valencia, Spain, July 2003.

[7] Hirsch, L., S., Gibbons, S., J., Kimmel, H., Rockland, R. and Bloom, J. (2003). "High School Students Attitudes to and Knowledge About Engineering". Proceedings of the $33^{\text {rd }}$ ASEE/IEEE Frontiers in Education Conference, Boulder, CO, November 2003.

[8] Gibbons, S., J., Hirsch, L., S., Kimmel, H., Rockland, R. and Bloom, J. (2004). "Middle School Students Attitudes to and Knowledge About Engineering". Proceedings of the 2004 International Conference on Engineering Education, Gainesville, FL, October 2004.

[9] Hirsch, L., S., Kimmel, H., Rockland, R. and Bloom, J. (2005). "Implementing Pre-engineering Curricula in High School Science and Mathematics". Proceedings of the $35^{\text {th }}$ ASEE/IEEE Frontiers in Education Conference, Indianapolis, IN., October 2005.

[10] American Society of Engineering Education. Engineering Education and the Science \& Engineering Workforce. Public Policy Internet Website. Retrieved March 2007 from http://www.asee.org.

[11] Besterfield-Sacre, M. \& Atman, C.J. "Survey design methodology: Measuring Freshman attitudes about engineering", ASEE Annual Conference Proceedings, Edmonton, Canada. June 1994.

[12] Besterfield-Sacre, M., Atman, C.J. \& Shuman, L.J. "Characteristics of freshman engineering students: Models for determining student attrition in engineering", Journal of Engineering Education, 86(2), 1997. 139-149. 
[13] Besterfield-Sacre, M., Atman, C.J. \& Shuman, L.J. “Engineering students attitudes assessment." Journal of Engineering Education, 87(2), 1998. 133-141.

[14] Fuller, H., Grant, S.C., Lawyer, K.C., Porter, R.L. \& Rajala, S.A. "Attitude about engineering survey: A study of confidence by gender", Fall 1995 and 1996, ASEE Annual Conference, Washington D.C. Sep. 19-20, 1997.

[15] Blaisdell, S. Social Cognitive theory predictors of entry into engineering majors for high school students, Unpublished Dissertation University of Arizona. 2000.

[16] Blaisdell, S. "Students' decision to enter engineering: How men and women differ." WEPAN Annual Conference, 2000. 243-251.

[17] Hartman, H. "A gender lens on Rowan University's College of engineering", Joint NAMEPA/WEPAN National Conference, Alexandria, Virginia, Apr. 21-24, 2001.32-38.

[18] Hofman, H. "Engineering as a career choice: Strengthening the weakest link" WEPAN National Conference, 2000. $137-143$

[19] Moreno, M., Besterfield-Sacre, M., Shuman, L.J., Wolfe, H. \& Atman, C.J. "Self assessed confidence in EC2000 Outcomes: A study of gender \& ethnicity differences across institutions", $30^{\text {th }}$ ASEE/IEEE Frontiers in Education Annual Conference. Kansas City, MO., Oct 2000. TA23-28.

[20] American Association of University Women (1992). How schools shortchange girls.

[21] Markow, D. and Moore, K. (2001). "Progress toward power: A follow-up survey of children and parents attitudes about math and science", National Action Council for Minorities in Engineering Research Letter, 9(1), 1-8.

[22] Blaisdell, S. "Students' decision to enter engineering: How men and women differ." WEPAN Annual Conference, 2000. 243-251.

[23] Cano, R., Kimmel, H., Koppel, N., and Muldrow, D. (2001). "A First Step for Women into the Engineering Pipeline". Proceedings of the $31^{\text {st }}$ ASEE/IEEE Frontiers in Education Conference, Reno, NV, October 2001.

[24] NJ Commission of Higher Education (2001). Higher education outcomes and high-tech workforce demands.

[25] Shoffner, M. F. and Vacc, N. N., "Careers in the mathematical sciences: The role of the school counselor. ERIC Digest", ERIC Clearinghouse on Counseling and Student Services, Greensboro, NC, 1999, pp. 1-4.

[26] Fouad, N A., "Career linking: An intervention to promote math and science career awareness", Journal of Counseling \& Development, Vol. 73, No 5, 1995, pp. 527-534.

[27] Conlin, M. (2003). The New Gender Gap, Business Week, May 26.

[28] Gibbons, M. "Women in Engineering”, ASEE Prism, Vol. 15, 2005.

[29] National Science Foundation. Women, Minorities, and Persons with Disabilities in Science and Engineering. Retrieved March 2007 from http://www.nsf.gov/statistics/wpmd.

[30] Asmundsen, S. J., "Career counseling with the college students in Career Development, Springfield, IL: Charles C. Thomas, 1992, pp.121-127.

[31] Jagacinski, C. M., "Engineering Careers: Women in a Male-Dominated Field", Psychology of Women Quarterly, Vol. 11, 1987, pp. 97-110

[32] Koppel, N., Cano, R., Heyman, S. (2002). “An Attractive Engineering Option for Girls" Proceedings of the $32^{\text {nd }}$ ASEE/IEEE Frontiers in Education Conference, Boston, MA, November 2002. 
[33] Koppel, N. B., Cano, R. M., Heyman, S. B., and Kimmel, H. (2003). "Single Gender Programs: Do they Make a Difference?" Proceedings of the $33^{\text {rd }}$ ASEE/IEEE Frontiers in Education Conference, Boulder, CO, November 2003.

[34] Cano, R., Berliner-Heyman, S., Koppel, N., Gibbons, S., Kimmel, H. (2004). "Evaluation of Summer Enrichment Programs for Womens' Students", Proceedings of the 2004 American Society for Engineering Education Annual Conference \& Exposition.

[35] Hirsch, L. S., Kimmel, H., Rockland, R. and Bloom, J. (2006). "A Study of the Impact of Enrichment Programs on Girls' Attitudes Towards Engineering”. Proceedings of the 2006 International Conference on Engineering Education, San Juan, PR, July 2006. 